\title{
FROM THE EDITORS' DESK From the Editors' Desk: Equal Rights for General Internists?
}

\author{
Carol K. Bates, $M D^{1,2}$ \\ ?. Harvard Medical School, Boston, MA, USA; ${ }^{2}$ Beth Israel Deaconess Medical Center, Boston, MA, USA
}

J Gen Intern Med 33(5):575

DOI: $10.1007 / \mathrm{s} 11606-018-4355-4$

(c) Society of General Internal Medicine 2018

$I_{\mathrm{q}}^{\mathrm{n}}$ $\mathrm{n}$ this issue, Cumbler et al. ${ }^{1}$ describe the results of a qualitative survey of hospitalists relating to academic advancement. Our editorial team was impressed with their ability to succinctly describe a qualitative study within the strict 700 word limit imposed by Concise Research Reports, and we encourage others to consider this publication category for qualitative work with streamlined outcomes.

It is no surprise that study respondents named protected time for research as one of three key ingredients to further their careers. While they did not study their colleagues in the outpatient world nor do a study on the actual amount of time available for academic pursuits, I have been thinking about the disparities between job descriptions for inpatient and outpatient generalists, and hypothesize that outpatient generalists are in greater need for protected time than their inpatient colleagues. We do not have hard data on the average job description, but I believe that the average full-time primary care internist hired to do patient care in an academic medical center would be scheduled for eight sessions per week with some combination of direct patient care and resident supervision. In my practice at Beth Israel Deaconess Medical Center in Boston, the job description was relatively cushy for many years with seven sessions per week, but new hires for several years now have eight scheduled sessions per week. Much has been written about the burdens of documentation and the work that many do, completing documentation on evenings and weekends. There are also lab results to be managed, and patient phone calls to be answered. The most effective time managers among us might reserve several hours of the two unscheduled sessions per week for academic work, if not spent on documentation, committee service, and other teaching obligations.

Contrast that with hospital medicine where a full-time job in academic medicine includes an average of 15 clinical shifts per month; community practice where presumably there are no expectations for scholarship has a mean of 19 clinical shifts per month. ${ }^{2}$ The rationale for this standard job description is the truly exhausting work during the weeks on service and the risk of burnout. There is also some clinical follow-up that hospitalists are expected to do, but there is substantial

Published online February 27, 2018 variability in those expectations. In one recent study, $28.5 \%$ of hospitalists felt that their responsibility for patients ended at discharge. $^{3}$

Hospital medicine is not unique in this structuring of fulltime work; our colleagues in emergency medicine and intensive care have similar work structures. Our primary care internists are also not unique; the absence of protected time during the standard work week is true for most whose work is standardized by days of the week rather than by weeks in the year. Those in hospital and ICU medicine do need recovery, but we do not know how time in these "off weeks" is spent and how much time is truly needed for recovery. In my internship, we had a MICU rotation in which we worked for 48 hours on and 48 hours off. I slept most those first days of two off, but had a memorable day skiing in August at Timberline Lodge in Oregon on the second day of one of those $48 \mathrm{~h}$ periods, made more memorable by the snow blindness that gradually subsided over my first day back on call. No one (including me) would advocate for 48 hour shifts now, but the time required for recuperation for grueling weeks may be substantially less than the time allotted, providing time for academic work.

As Associate Dean for Faculty Affairs at Harvard, I worry about the double standard that exists for our clinical faculty who have essentially no protected time in comparison with those who have days or weeks that are free of clinical responsibilities. There is no question that academic hospitalists could benefit from more protected time to boost their scholarship, and there is no question that they are vital to our collective missions and to SGIM, but given financial constraints, let us look first at the distribution of existing protected time and the realistic likelihood of academic productivity in our divisions more broadly.

Corresponding Author: Carol K. Bates, MD; Harvard Medical School, Boston, MA, USA (e-mail: Carol_Bates@hms.harvard.edu).

\section{REFERENCES}

1. Cumbler E, Rendón P, Yirdaw E, et al. Keys to career success: Resources and barriers identified by early-career academic hospitalists. JGIM 2018. https://doi.org/10.1007/s11606-018-4336-7

2. Hinami K, Whelan CT, Miller JA, Wolosin RJ, Wetterneck TB. Hospitalist Practice Models. J Hosp Med 2012;5;402-410. https://doi. org/10.1002/jhm. 1907

3. Burke RE, Ryan P. Postdischarge clinics: Hospitalists attitudes and experiences. J Hosp Med 2013;8:578-81. 